\title{
Design Parameters of a Screw Extruder for Biofuel Production
}

\author{
Kirill Epifancev* \\ Saint Petersburg University of Aerospace instrumentation (SUAI), Saint Petersburg, Russia
}

*Corresponding author: Kirill Epifancev, Saint Petersburg University of Aerospace instrumentation (SUAI), Saint Petersburg, Russia.

Received Date: March 14, 2019

Published Date: April 17, 2019

\begin{abstract}
The development of non-destructive testing in Saint-Petersburg State University of aerospace in-strumentation (SUAI) is reflected in the appearance of new terms that are used in practice, scientific papers and technical descriptions. Non-destructive control increasingly contacts with adjacent areas involved in assessing the actual technical condition of the facilities, determining the possibility of their further operation and the terms of safe operation (resource problem). In this paper, the methods of nondestructive testing of industrial objects, as well as various types of this method, such as magnetic, electric, which are used to create new laboratory work in the educational process.
\end{abstract}

Keywords: Organic wastes; Extruder; Molding die block; Pelletising; Modeling; Molding parameters

\section{Introduction}

An extruder working element is a combination of screw and die block that define the shape, size and quality of finished products (fuel pellets). The die block comprises draw dies that define the extruder performance and the quality of Pelletised biofuel. The selection and justification of dimensions, section shapes and the number of draw dies in the die block allow producing pellets with specific quality characteristics. The Pelletising process is controlled through the following parameters: current, screw speed, feed humidity, die block and draw die shapes, biomass composition, and the number of pre-treatments [1]. The biomass Pelletising process is accompanied by sufficiently high pressure that is required to destruct residual fibers and compact the processed mass [2]. Along with positive contribution of pressure into the quality of fuel produced, power necessary for molding is substantially increased [3].

\section{Material and Study Methods}

The studies of the extruder molding process were carried out based on peats of various humidity, and to study the power consumption of the unit in processing, MN-2 screw extruder was selected (Figure 1).

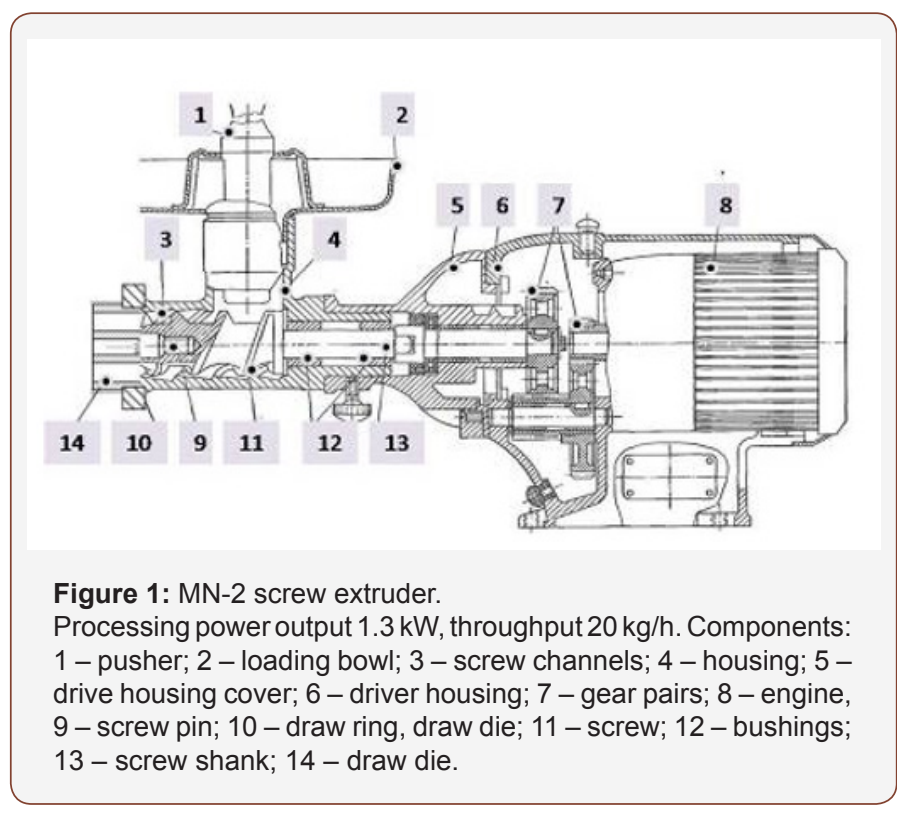

The MN-2 screw extruder engine is connected to a Huyndai N100 frequency converter to change the screw speed and monitor any changes in current, voltage and rpm depending on various 
humidity of the peat to be processed. A test bed is represented in Figure 2 (Figure 2).
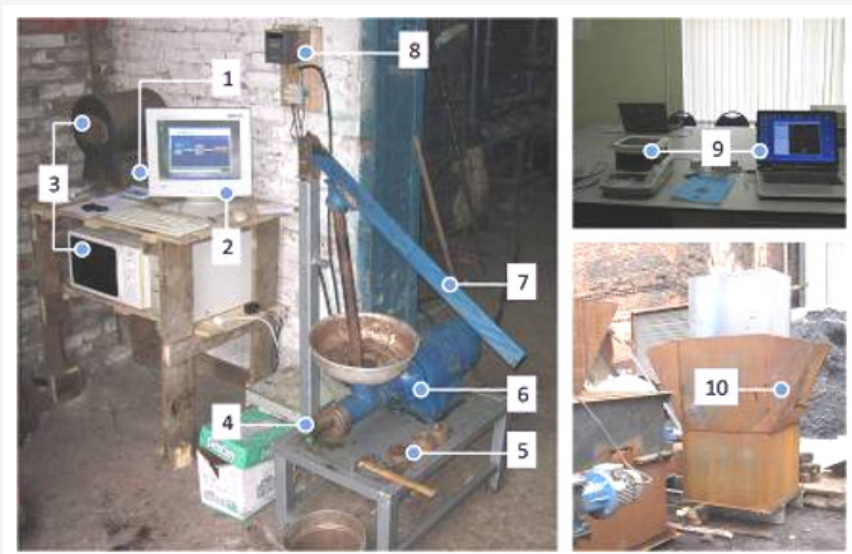

Figure 2: Test bed for studying the cold extrusion process. 1 - balance $(0.01 \mathrm{~g}) ; 2$ - computer with $\mathrm{N} 100$ software package installed to analyze the frequency converter operation; 3 - muffle furnace and microwave oven to dry individual pellets; 4 - fuel pellet produced; 5 - set of draw dies; 6 - extruder based on 722-2M meat grinder; 7 - lever to feed peat into the extruder's chamber; 8 - HyundaiN100 frequency converter; 9 - And electronic moisture tester; 10 - fluidized bed drier.

According to the works of Chistyy, laboratory and full-scale tests of screw extruders revealed that, in standard condition (humidity of 50\%), the quality of fuel pellets depends on the ratio of the draw die length to its diameter and may significantly vary depending on the shape of holes where raw materials are fed [4]. In case a draw die shows an insufficient capability of relaxation, after molding, it may pro-duce pellets with uneven surfaces. Non-relaxed materials coming out of the draw die rapidly gain the required relaxation peak followed by the diameter being quickly increased, which creates a central crack that substantially grows in size when drying and when the moisture goes out of pores, so that all bonds between particles are broken and the pellets tendency to crumble increases (Figure 3).

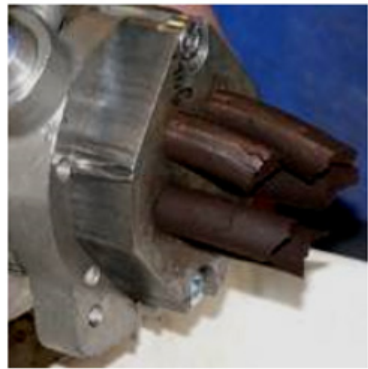

a) no pre-relaxation

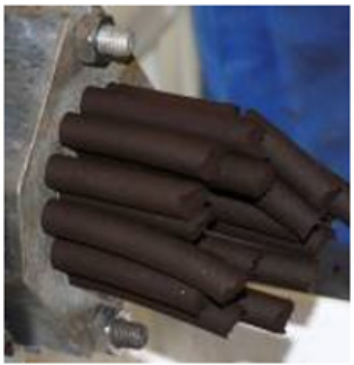

b) pre-relaxation provided
Figure 3: Pellet molding process.

During the experiment, a frequency converter allows monitoring the engine speed and, con-sequently, the screw speed. Experiments have been carried out intended to reveal the maximum extruder throughput when crushing peat with $75 \%$ humidity in case of no processing, single or double processing. For this purpose, $180 \mathrm{~g}$ of peat were placed into a preliminary cleaned extruder chamber to be processed for 15 seconds. According to one of the suggestions, the screw sometimes fails to capture the sufficient amount of materials with its vanes at various speeds when feeding the peat into the screw chamber.

\section{Study Result}

In case of high biomass humidity, the dry substance concentration in a volume unit is low, and interaction forces between particles are not too high in this case. Insufficient resistance to set-ting from the framework of plant residues and the strain in the drying surface layer may cause cracking [5-6]. When the initial humidity is reduced, the framework of plant residues also shows significant resistance to setting, but as the peat dries out, the increased number of particle contacts pro-motes more intensive development of attraction forces between them and better compaction (Table 1) [7].

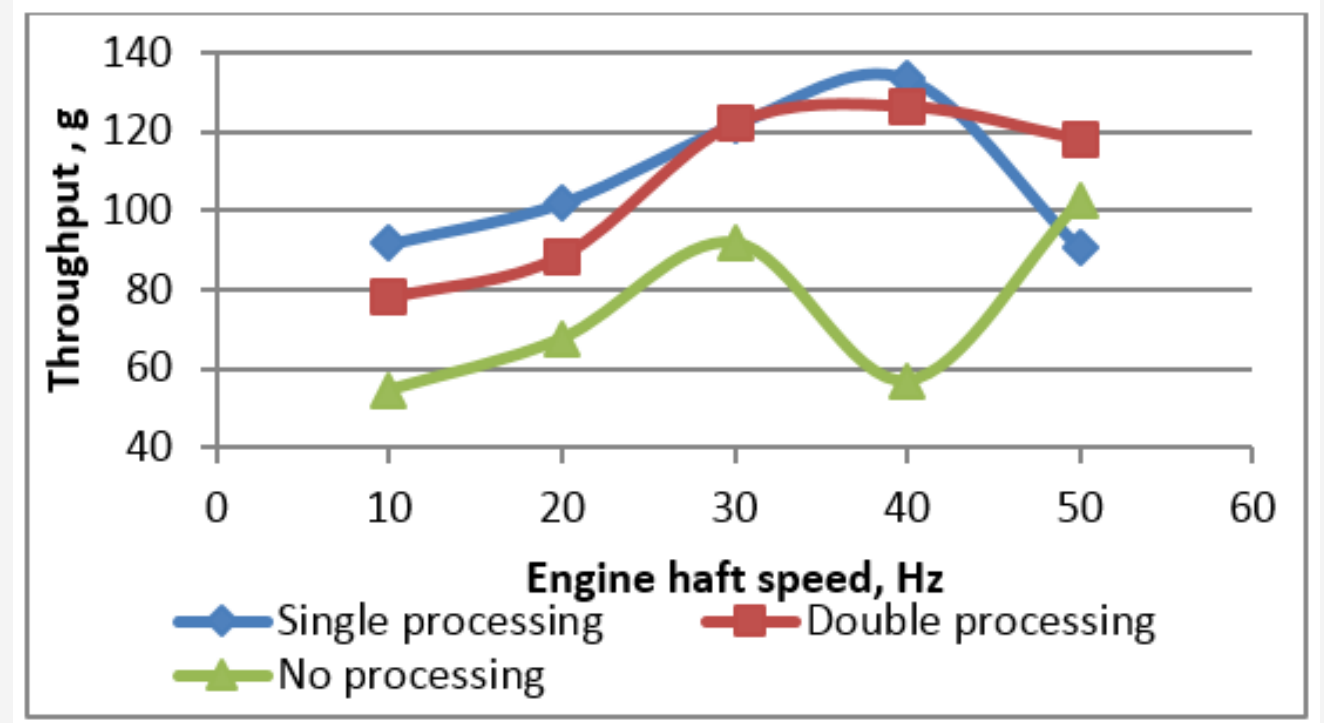

Figure 4: Extruder throughput-to-rpm dependence diagram. 
Table 1: Throughput changes depending on the screw rpm.

\begin{tabular}{|c|c|c|c|c|c|c|c|}
\hline \multirow{2}{*}{ No. } & \multirow{2}{*}{ RPM } & \multicolumn{2}{|c|}{$\begin{array}{c}\text { Amount Produced from Biomass } \\
\text { with no pre-Relaxation, }\end{array}$} & \multicolumn{2}{c|}{$\begin{array}{c}\text { Amount Produced from Biomass } \\
\text { after Single Pre-Relaxation, } \mathbf{g}\end{array}$} & \multicolumn{2}{|c|}{$\begin{array}{c}\text { Amount Produced from Biomass } \\
\text { after Double Pre-Relaxation, } \mathbf{g}\end{array}$} \\
\cline { 3 - 8 } & & $\mathbf{1 5} \mathbf{~ s e c}$ & $\mathbf{6 0} \mathbf{~ m i n}$ & $\mathbf{1 5} \mathbf{~ s e c}$ & $\mathbf{6 0} \mathbf{m i n}$ & $\mathbf{1 5} \mathbf{s e c}$ & $\mathbf{6 0} \mathbf{m i n}$ \\
\hline 1 & 10 & 54.5 & 13,080 & 91.7 & 22,008 & 77.9 & 18,696 \\
\hline 2 & 20 & 67.6 & 16,224 & 102 & 24,480 & 88.5 & 21,240 \\
\hline 3 & 30 & 92 & 22,080 & 121.7 & 29,208 & 122 & 29,280 \\
\hline 4 & 40 & 56.8 & 13,632 & 133.4 & 32,016 & 126.3 & 30,312 \\
\hline 5 & 50 & 102.4 & 24,576 & 90.6 & 21,744 & 118 & 28,320 \\
\hline
\end{tabular}

During processing, a high amount of materials sticks to the guiding channels of the housing and the screw surface. The material is intensively processed in the thin wall-adjacent layer, and this becomes the primary cause of the sticking of the material to the channel walls and reduced through-put (Figure 4).

Table 2: Current changes depending on peat processing.

\begin{tabular}{|c|c|c|c|}
\hline \multirow{2}{*}{ No. } & \multirow{2}{*}{ Humidity \% } & \multicolumn{2}{|c|}{ Current, A } \\
\cline { 3 - 4 } & & Single Processing & Double Processing \\
\hline 1 & 57 & 5.7 & 6.3 \\
\hline 2 & 64 & 1.9 & 2.3 \\
\hline 3 & 72 & 1.7 & 2.4 \\
\hline
\end{tabular}

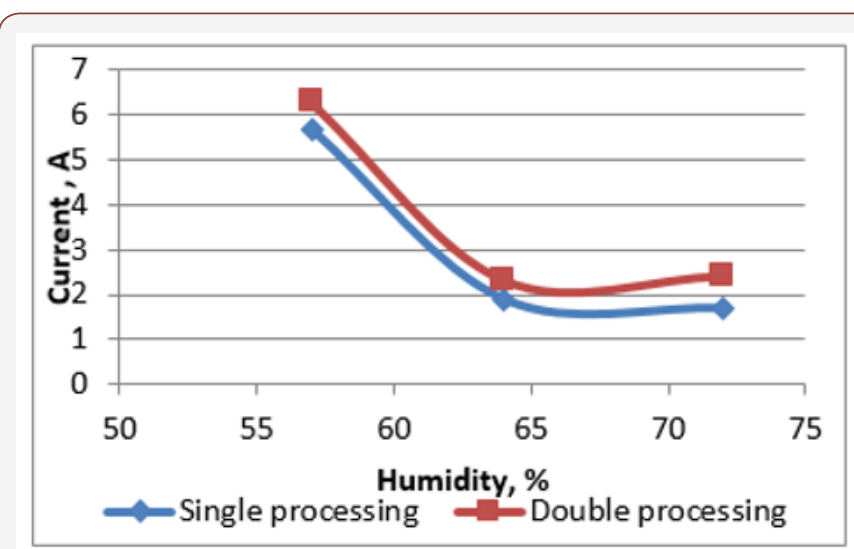

Figure 5: Current to peat humidity dependence.

The shaft rpm was adjusted by a frequency converter to make the screw decelerate slower. As is well-known, the period of time when the pressure affects the biomass varies within fractions of a second in molding mechanisms of the extruder [8]. Studying the energy dependency of peat mechanical processing is of greatest importance for peat brick production. The current measurement results in the production of peat of various humidity and degree of fineness are given in Table 2 and Figure 5 (Table 2 \& Figure 5).

The operation analysis of screw die blocks of various designs was done by creating a 3D simulation model of operation in the Para View software environment. For simulation purposes, twelve die block sizes were modeled whose surface was divided by using the finite element meth-od. The area where differential equations are solved is divided into the finite number of subregions (elements). A type of the approximation function is randomly selected in each element. In the simplest case, this is a first-degree polynomial. The approximation function equals zero beyond its element. The values of the function at the borders of elements (in nodes) for the solution of tasks are unknown in advance [9]. The coefficients of approximation functions are usually sought based on the equality of adjacent function values at the borders between elements (in nodes). These coefficients are then expressed through the values of functions in the nodes of the elements. The system of linear algebraic equations is produced. The number of equations equals the number of unknown values in nodes where the solutions of the initial system are sought and is directly proportional to the number of elements and limited by the PC capabilities only. Since each element is connected to a limited number of adjacent ones, the system of linear algebraic equations is sparsely populated, which substantially simplifies its solution. 3D models of the extruder die block are given in Figures 6 \& 7.
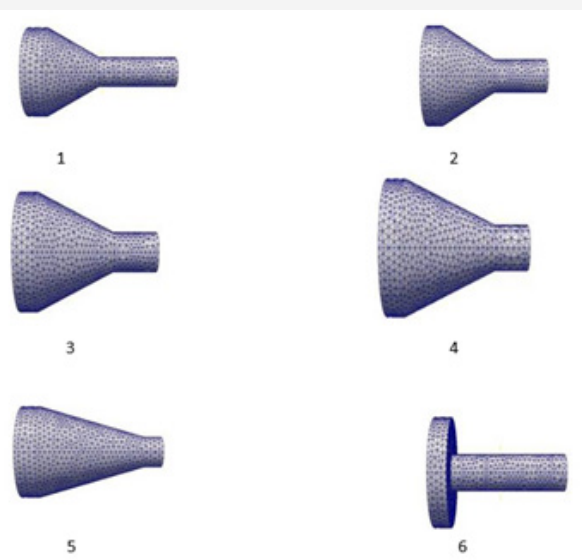

Figure 6: Types of 3D modules of extruder die block with d1/ d2 $=1: 3$. Modeled inclination angles: $1-15^{\circ} ; 2-17.5^{\circ} ; 3-20^{\circ}$; $4-25^{\circ} ; 5-30^{\circ} ; 6-0^{\circ}$.

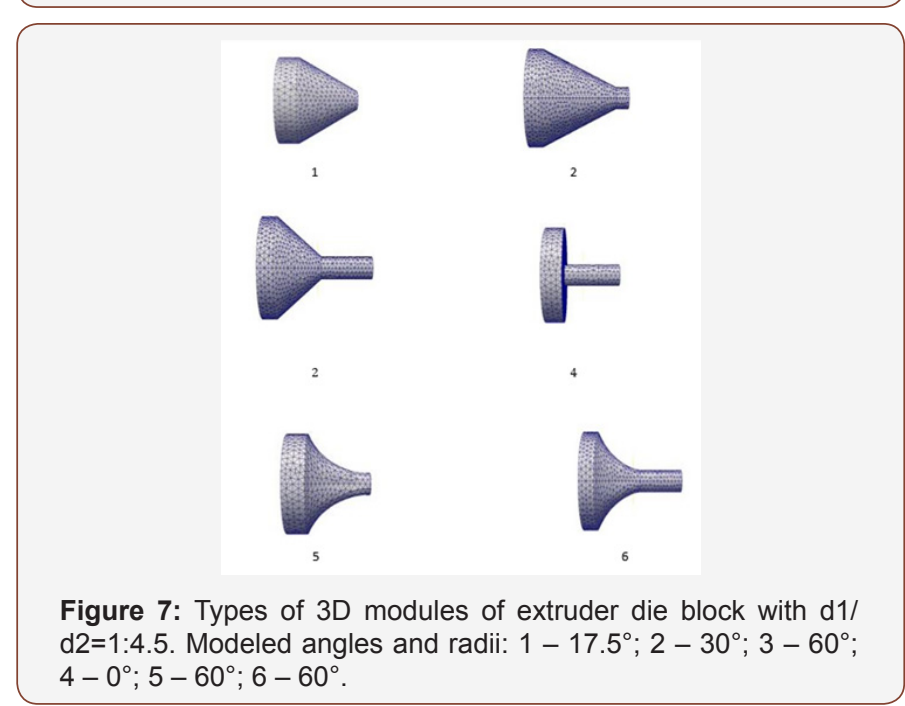


When calculating the modeling forces, several force parameters affecting the screw could be analyzed (Figure 8).

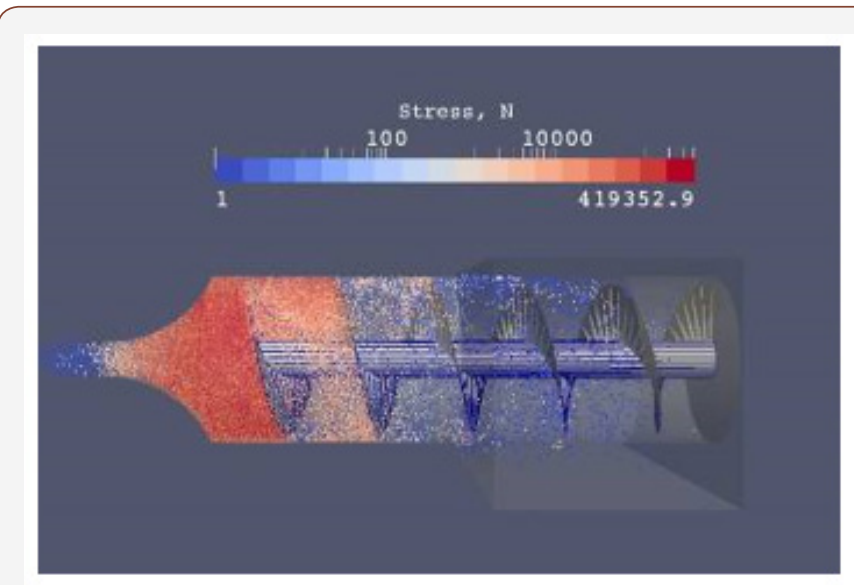

Figure 8: Exemplary data analysis in software.

The results of 3D modeling of die block are summarized in Table 3.

Table 3: 3D modeling results.

\begin{tabular}{|c|c|c|c|c|c|c|}
\hline No. & $\begin{array}{c}\text { Head } \\
\text { Shape }\end{array}$ & $\mathbf{d}_{\mathbf{1}} / \mathbf{d}_{2}$ & $\mathbf{L}, \mathbf{m m}$ & $\mathbf{v}, \mathbf{m} / \mathbf{s}$ & $\begin{array}{c}\text { Qnorm, } \\
\text { KPa }\end{array}$ & $\begin{array}{c}\text { Qtang, } \\
\text { KPa }\end{array}$ \\
\hline 1 & $0^{\circ}$ & $1 / 4.5$ & 70 & 6.553 & 589 & 62 \\
\hline 2 & $17.5^{\circ}$ & $1 / 4.5$ & 130 & 6.56 & 559 & 60.3 \\
\hline 3 & $30^{\circ}$ & $1 / 4.5$ & 130 & 6.7 & 583 & 75.7 \\
\hline 4 & $60^{\circ}$ & $1 / 4.5$ & 70 & 6.7 & 424 & 37.9 \\
\hline 5 & $\mathrm{R} 60$ & $1 / 4.5$ & 70 & 6.4 & 419.35 & 75.7 \\
\hline 6 & $\mathrm{R} 60$ & $1 / 4.5$ & 100 & 7.11 & 746.3 & 84.6 \\
\hline 7 & $0^{\circ}$ & $1 / 3$ & 130 & 7.1 & 773 & 93.1 \\
\hline 8 & $15^{\circ}$ & $1 / 3$ & 130 & 5.94 & 421.39 & 42.44 \\
\hline 9 & $17.5^{\circ}$ & $1 / 3$ & 130 & 6.36 & 501.99 & 55.716 \\
\hline 10 & $20^{\circ}$ & $1 / 3$ & 130 & 6.36 & 501.9 & 55.716 \\
\hline 11 & $25^{\circ}$ & $1 / 3$ & 130 & 6.51 & 501.9 & 55.71 \\
\hline 12 & $30^{\circ}$ & $1 / 3$ & 130 & 6.57 & 571.8 & 66.217 \\
\hline
\end{tabular}

The screw extruder die block No. 5 shows the most sustainable parameters, which corresponds to optimal values between the minimal force at the screw shaft and the maximum mass flow velocity.

\section{Discussion of Result}

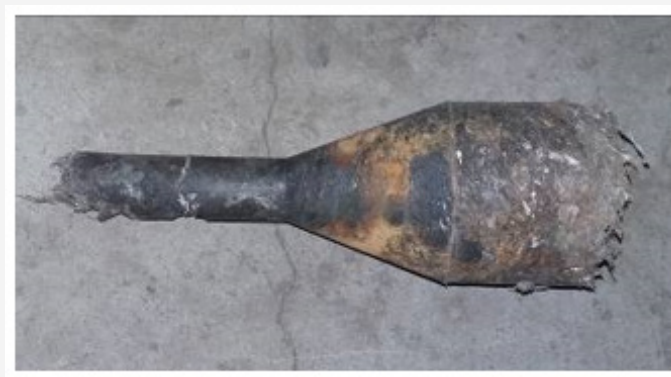

Figure 9: Stopper plug extracted from the draw die.

Based on the theoretical studies, experimental molding was carried out, and limit values of screw extruder operation were determined. The experimental humidity of the blend molded was determined: $70-72 \%$. The humidity of the molded blend of $50-60 \%$ causes stopper plugs to be formed in the draw die, which causes the extruder to stop (Figure 9).

The humidity of the molded blend of $75 \%$ causes shapeless fuel pellets to be formed with insufficient strength characteristics. To select sustainable parameters of the molding process, we assume the data summarized in Table 4 .

Table 4: Selecting sustainable parameters of the molding process.

\begin{tabular}{|c|c|c|}
\hline No. & Parameter & Indicator \\
\hline 1 & Current & $1.7 \mathrm{~A}$ \\
\hline 2 & Shaft speed & $40 \mathrm{rpm}$ \\
\hline 3 & Die block shape & R60, d1 $/ \mathrm{d} 2=1 / 4.5$ \\
\hline 4 & Humidity & $70-72 \%$ \\
\hline 5 & No. of pre-processings & single \\
\hline
\end{tabular}

Narrowing the draw die cylindrical section along the catenary line allows significantly improving the quality of the molded mass as compared to a right narrowing cone and the draw die right angle. The following circumstances can serve as justification of narrowing the draw die along the catenary line: on the one hand, pressure is exponentially reduced along the channel length due to energy losses for mass deformation and friction against the draw die wall, and on the other hand, the mass resistance to deformation grows exponentially as the material moves in the draw die. The total of these dependencies yields a hyperbolic cosine a catenary line. Therefore, taking these processes into account simultaneously creates better conditions for relaxation processes $[10,11]$.

\section{Conclusion}

By the example of structural and mechanical characteristics of the peat paste, the studies showed that it obeys the Bingham plastic model during deformation. Based on the experiments, the draw die design of the press matrix has been justified. The draw die made of a catenary line ensures the friction forces to be reduced between the peat mass and the draw die internal surface comprised of molding and calibrating parts. It has been established that the primary functional characteristics of a high-quality screw extruder include as follows: precision of the geometric characteristics of the shape (deviations of dimensions, deviations from a straight shape), molding speed, readiness coefficient (maximum period between cleaning operations, cleaning and maintenance convenience, time required to mount and dismount the tool, convenient setting of various operating modes), and the durability and reparability of the tool.

\section{Acknowledgement}

None.

\section{Conflict of Interest}

No conflict of interest.

\section{References}

1. Sing CY, Aris MS (2014) The Effect of Mixing Coal with Biomass in Solid Fuel Briquettes. Advanced Materials Research 856: 338-342. 
2. Liu RC, Huang B, Lv W, Gao Q, Wang XY (2015) Biomass Molding Technology and the Research State of Biomass Binder. Applied Mechanics and Materials 700: 3-6.

3. Mitan NMM, Azmi AH, Nur Fathiah MN, Se SM (2015) Binder Application in Durian Peels Briquette as a Solid Biofuel. Applied Mechanics and Materials 761: 494-498.

4. Chistyy IN (1980) Proizvodstvo granulirovannogo torfa [Production of Pelletised Peat]. Minsk.

5. Kocserha I, Kristály F (2010) Effects of Extruder Head's Geometry on the Proper-ties of Extruded Ceramic Products. Materials Science Forum 659: 499-504.

6. Bogatov BA (1985) Upravlenie protsessom razrabotki torfyanykh mestorozhdeniy [Managing the Development Process of Peat Bogs] Minsk: Vysshaya shkola.

7. Kosov VI (2005) Torf i sapropel' - moshchnyy energeticheskiy geoekologicheskiy po-tentsial Rossii [Peat and Sapropel - Powerful Energetic and Geoecological Potential of Russia]. In: Vestnik XXI: razvedka, dobycha, pererabotka poleznykh iskopaemykh (Bulletin 21: Survey, Devel-opment and Processing of Fossil Fuels) Intermet Inzhiniring, Moscow, pp. 212-223.

8. Tsereshinsky S (1977) Issledovanie energoemkosti protsessa granulirovaniya verkhovogo torfa nizkoy stepeni razlozheniya: Avtoref. dis.kand. tekhn. nauk [Studying the Power Capacity of the LowDestruction Terrestrial Peat Pelletizing Process (Ph.D. Thesis Abstract)]. Kaliningrad: Kali-ningrad Polytechnic Institute.

9. Benbow J, Bridgwater J (1993) Paste Flow and Extrusion. Oxford: Clarendon Press, UK.

10. Nikulin AN, Kovshov SV, Epifancev KV, Korshunov GI (2014) The Research of Possibility to Use the Machine for Biofuel Production as a Mobile Device for Poultry Farm Waste Recycling. Life Science Journal 11(4): 464-467.

11. Epifancev K, Nikulin A, Kovshov S, Mozer S, Brigadnov I (2013) Modeling of Peat Mass Process Formation Based on 3D Analysis of the Screw Machine by the Code YADE. American Journal of Mechanical Engineering 1(3): 73-75. 